\title{
CORONARY ARTERY BYPASS IN DEXTROCARDIA
}

\author{
Lokesh Shekher Jaiswal1, Milind Padmakar Hote ${ }^{2}$
}

${ }^{1}$ Associate Professor, Department of Cardiothoracic and Vascular Surgery, B. P. Koirala Institute of Health Sciences, Dharan, Nepal. 2 Professor, Department of Cardiothoracic and Vascular Surgery, All India Institute of Medical Sciences, New Delhi.

HOW TO CITE THIS ARTICLE: Jaiswal LS, Hote MP. Coronary artery bypass in dextrocardia. J. Evolution Med. Dent. Sci. 2017;6(58):4336-4337, DOI: 10.14260/Jemds/2017/937

\section{PRESENTATION OF CASE}

A 64 years old woman with known situs inversus and dextrocardia presented with complaints of right-sided chest discomfort on exertion since 2 months and history of acute coronary syndrome 1 month back. She was having class 3 symptom for past 10 days. She was a known case of type 2 diabetes mellitus and hypertension for past 15 years. There was no family history of coronary artery disease. Her physical examination was normal except for dextrocardia. Echocardiography showed situs inversus with dextrocardia with moderate left ventricular systolic and diastolic dysfunction. All the valves were essentially normal with regional wall motion abnormality (RWMA) in anteroseptal and apical region. Coronary angiography revealed left main coronary artery disease. Left anterior descending artery (LAD) showed significant osteoproximal obstruction with diffuse distal disease; circumflex showed significant proximal and obtuse marginal (OM1) disease. Right coronary artery (RCA) was normal. She underwent on-pump coronary artery bypass surgery. Intraoperatively, obtuse marginal branch was seen to be very small and not graftable. Right internal mammary artery (RIMA) was harvested and all anastomoses were done with surgeon standing on left side of the patient. RIMA was grafted to left anterior descending artery (LAD). Saphenous vein graft was used to bypass the diagonal artery. There were no postoperative complications and ionotropic requirements. She was extubated after 6 hours and transferred to ward on next day. She was discharged after six days.

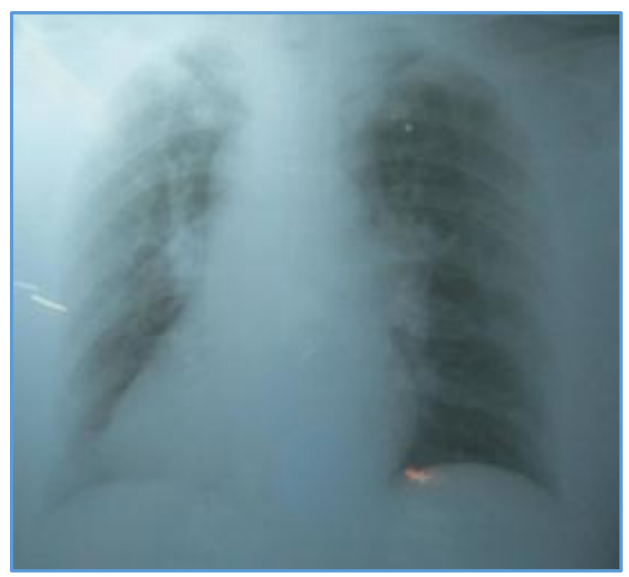

Figure 1. CXR showing Dextrocardia

Financial or Other, Competing Interest: None.

Submission 16-06-2017, Peer Review 09-07-2017,

Acceptance 15-07-2017, Published 20-07-2017.

Corresponding Author:

Lokesh Shekher Jaiswal,

Department of Surgery,

Unit of CTVS, BPKIHS,

Dharan, Nepal.

E-mail:lokesh_shekher@yahoo.com

DOI: $10.14260 / \mathrm{jemds} / 2017 / 937$

\section{(c) (i) () $\odot$}

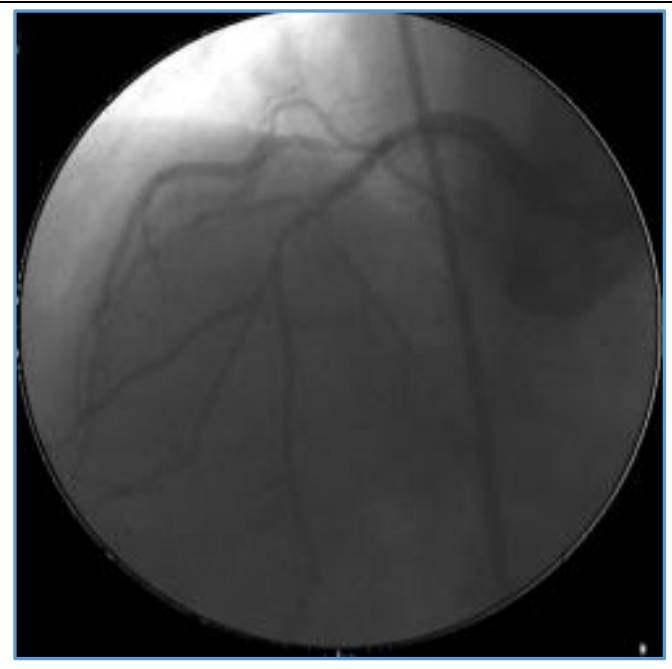

Figure 2

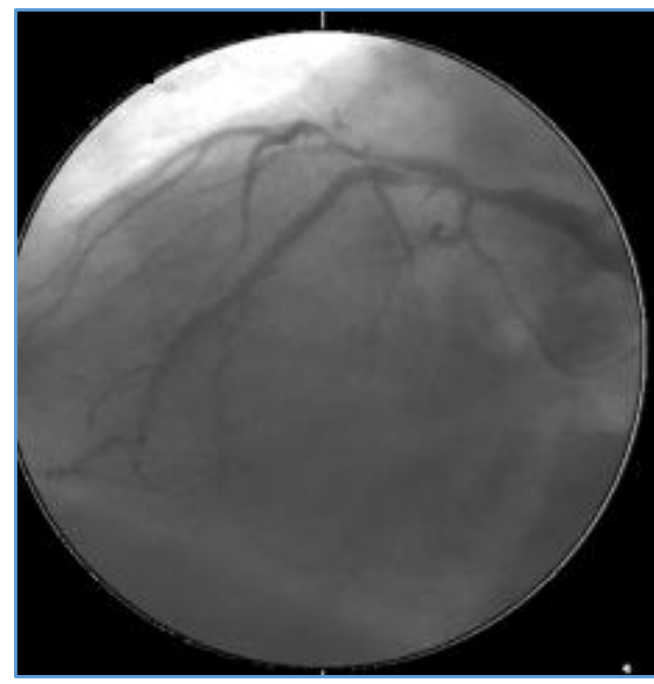

Figure 3

Figure 2 and 3. Showing LM Disease and Significant LAD Obstruction

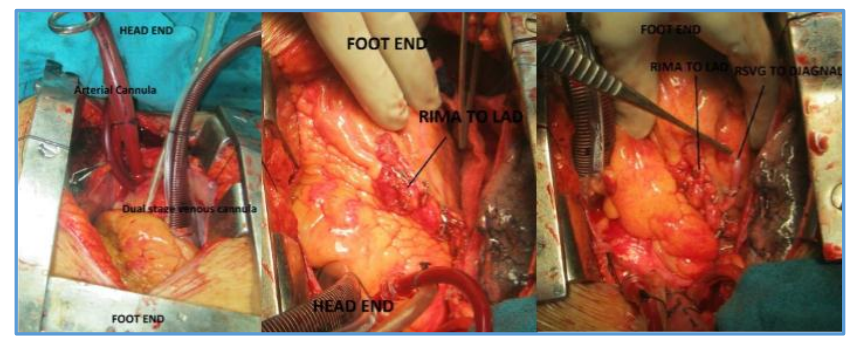

Figures 4. Showing Cannulation, RIMA to LAD Anastomosis and RSVG to Diagonal Anastomosis 


\section{DIFFERENTIAL DIAGNOSIS}

Dextrocardia is the malposition of the heart, in which it is situated on the right side of the thorax. It can occur in situs solitus or in situs inversus condition. Incidence in general population of situs inversus with dextrocardia is estimated to occur at $1 / 10000.1,2$ It usually occurs without any coexisting congenital heart disease. The person with this malposition can live long enough to develop atherosclerotic coronary artery disease with same frequency as that of normal population. ${ }^{3,4}$ Coronary artery disease (CAD) in dextrocardia is not so common and there are only few cases reported worldwide.

\section{DISCUSSION OF MANAGEMENT}

Myocardial revascularisation in dextrocardia is not a commonly performed procedure. There are case reports from different authors. There are specific issues regarding the technique of operation like the position of surgeon, which internal mammary artery to use and whether to do off-pump or on-pump surgery. Some have used right IMA to revascularise LAD.5,6,7 Others have used saphenous vein as graft. ${ }^{8,9}$ The long patency of arterial graft is well established, so we used internal mammary artery to bypass LAD. In dextrocardia, use of left IMA would raise the issue of inappropriate length and of crossing the midline. Therefore, we used right side internal mammary artery. In harvesting RIMA and to anastomose to LAD, it was found to be technically easier when surgeon stands on left side of patient, as it allows the complete and normal view of operative field. There are reports of off-pump surgery, but we chose to do onpump as we routinely do on-pump surgery. We did not change the position of cardiopulmonary bypass (CPB) machine and there was no difficulty pertaining to this.

\section{FINAL DIAGNOSIS}

In conclusion, the revascularisation of patient with dextrocardia can be easily accomplished with minor adjustments in conduit choice and surgeon's position to achieve good results.

\section{REFERENCES}

[1] Rosenberg HN, Rosenberg IN. Simultaneous association of situs inversus, coronary heart disease and hiatus hernia: report of a case and review of literature. Ann Intern med 1949;30:851-9.

[2] Torgersen J. Genetic factors in visceral asymmetry and in the development and pathologic changes of the lungs, heart and abdominal organs. Arch Pathol 1949;47(6):566-93.

[3] Hymes KM, Gau CT, Titus JL. Coronary heart disease in situs inversus totalis. Am J Cardiol 1973;31(5):666-9.

[4] Ptashkin D, Stein E, Warbasse JR. Congenital dextrocardia with anterior wail myocardial infarction. Am Heart J 1967;74(2):263-7.

[5] Erdil N, Cetin L, Sener E, et al. Situs inversus and coronary artery disease. Asian Cardiovasc Thorac Ann 2002;10(1):53-4.

[6] Abensur H, Ramires JA, Dallan LA, et al. Right mammary coronary anastomosis in a patient with situs inversus. Chest 1988;94(4):886-7.

[7] Mesa JM, Aroca A, Frutos A, et al. Situs inversus and myocardial revascularization. Case report. J Cardiovascu Surg 1995;36(6):571-2.

[8] Grey DP, Cooley DA. Dextrocardia with situs inversus totalis: cardiovascular surgery in these patient with concomitant coronary artery disease. Cardiovasc Dis Bull Texas Heart Inst 1981;8(4):527-30.

[9] Irvin RG, Ballanger JF. Coronary artery bypass grafting in patient with situs inversus. Chest 1982;81:380-1. 